\title{
1992 ANNUAL MEETING CHILD CARE SERVICE
}

\section{REGISTRATION FORM}

The American Political Science Association will sponsor a Child Care Service at the 1992 Annual Meeting in Chicago. Child care will be available daily in the Palmer House Hilton from Thursday, September 3 to Sunday, September 6. The hours of operation are from 8:30 a.m. to 10:00 p.m. except on Sunday, September 6 when the hours of operation will be from 8:30 a.m. to 12:00 p.m.

"Club Kid" child care is available for unlimited use to children of registrants at the 1992 Annual Meeting. Parents will be asked to complete a tentative schedule following confirmation of their child care service registration. Nutritious snacks and beverages will be provided. Lunch and dinner must be provided by the parents. Diapers, special milk or formula, as well as any written special feeding instructions should be supplied by the parents.

To register a child for the "Club Kid" child care service you must complete this form and return it to APSA by July 17, 1992. A $\$ 25.00$ non-refundable deposit is required for each registered child. The deposit and registration form must be submitted together to APSA.

Parents' Name:

Home Address:

Home Phone \#:

Please list child/children (include name, age, and weight)

1.

2.

3.

List name, address, and telephone number of any legal next of kin we may contact if you are unreachable. If this contact is necessary, a collect telephone call will be placed to the next of kin listed below for notification.

(Name) (City, State) (Telephone \#)

We, the parents of the child/children listed above, hereby give our consent to any licensed physician at, with, or from any accredited hospital to administer any medical care or medication to the above named child/children during our absence from them while attending the American Political Science Aasociation Annual Meeting at the Palmer House Hilton, Chicago, September 3-6, 1992.

Mother's Signature

Date

Father's Signature

Date

TO RESERVE A PLACE IN THE APSA CHILD CARE SERVICE, ALL REGISTRATION FORMS AND DEPOSITS MUST BE RECEIVED AT APSA BY JULY 17, 1992. THERE WILL BE LIMITED ON SITE REGISTRATION. ON SITE REGISTRATION WILL REQUIRE A $\$ 40.00$ NON-REFUNDABLE DEPOSIT PER CHILD.

Return completed form and deposit to:

Child Care Coordinator

American Political Science Association

1527 New Hampshire Avenue, N.W.

Washington, DC 20036 